\title{
A valid, accurate, office based non-radioactive test for gastric emptying of solids
}

\author{
J S Lee, M Camilleri, A R Zinsmeister, D D Burton, L J Kost, P D Klein
}

\begin{abstract}
Background-Current breath tests for measurement of gastric emptying of solids are expensive, possibly inaccurate, and require cumbersome calculations.

Aims-We wished to validate a simplified solid gastric emptying test using a $\left[{ }^{13} \mathrm{C}\right]$ Spirulina platensis breath test for accurate results relative to scintigraphy. Subjects-Thirty healthy volunteers.

Methods-We measured gastric emptying of egg containing $\left[{ }^{13} \mathrm{C}\right] S$ platensis and ${ }^{99 \mathrm{~m}} \mathrm{Tc}$ sulphur colloid by breath ${ }^{13} \mathrm{CO}_{2}$ and scintigraphy over six hours. A generalised linear regression model was used to predict $t_{1 / 2}$ and $t_{L A G}$ by scintigraphy from breath ${ }^{13} \mathrm{CO}_{2}$ data. The model was cross validated and normative data calculated for a prepacked $\left[{ }^{13} \mathrm{C}\right] \mathrm{meal}$.

Results-Regression models using all breath data over six hours, for the first three hours, and for samples at 75, 90, and 180 minutes ("reduced model") predicted $t_{1 / 2}$ and $t_{L A G}$ values similar to scintigraphy ( $t_{\text {LAG }} 43$ (SD 12) min; $t_{1 / 2} 100$ (20) min). Standard deviations of differences in $t_{1 / 2}$ and $t_{L A G}$ between scintigraphy and the "reduced model" were both 10 minutes. Gastric $t_{1 / 2}$ for the prepacked $\left[{ }^{13} \mathrm{C}\right]$ meal was 91 (15) $\mathrm{min}$ (10-90\% range: $74-118)$.

Conclusion-The $\left[{ }^{13} \mathrm{C}\right] S$ platensis breath test and a simple formula using breath ${ }^{13} \mathrm{CO}_{2}$ at baseline, 90, and 180 minutes measured gastric emptying $t_{1 / 2}$ for solids with results that were comparable with scintigraphy.

(Gut 2000;46:768-773)
\end{abstract}

Research Unit, Mayo Clinic and Mayo

Foundation, Rochester, Minnesota, USA

J S Lee

M Camilleri

D D Burton

L J Kost

Section of

Biostatistics, Mayo

Clinic and Mayo

Foundation, Rochester,

Minnesota, USA

A R Zinsmeister

Meretek Diagnostics, Houston, Texas, USA

P D Klein

Correspondence to: Dr M Camilleri, Mayo Clinic, Gastroenterology Research Unit, 200 First St SW, Rochester, MN 55905, USA.

Accepted for publication 25 November 1999
Keywords: stable isotope; breath test; gastric emptying

Gastric emptying of solids is used to screen for gastric motor disorders. Two parameters that are clinically useful are $t_{1 / 2}$ and the proportion emptied at four hours ${ }^{1-3}$; these reflect overall emptying functions. The time for the first $10 \%$ to empty (or lag time ${ }^{1}$ ) is a marker for the ability of the stomach to triturate solid food to a particle size that can be emptied $\left(<2 \mathrm{~mm}^{4}\right)$. These measurements $\left(t_{\text {LAG }}, t_{1 / 2}\right)$ are best estimated by scintigraphy and the state of the art analysis uses a power exponential or a nonlinear model. ${ }^{1-5}$

Stable isotope breath tests were recently introduced to measure gastric emptying of solids because of their potential advantages ${ }^{6-9}$ which include performance of the test at the bedside or in the community; remote laboratory automated analysis; application at sites where gamma camera facilities are not avail- able; and avoidance of radiation, facilitating research studies in children and pregnant women.

The lack of validity for interindividual comparisons is a significant pitfall ${ }^{10}$; inaccuracies of the test may result partly from the nonlinear models used to fit the cumulative breath ${ }^{13} \mathrm{CO}_{2}$ recoveries. In the breath test, the total gastric residual is unknown and is estimated by a formula where time is infinite and ${ }^{13} \mathrm{CO}_{2}$ excretion is assumed to have reached a steady state. Estimates of gastric half-emptying time $\left(t_{1 / 2}\right)$ and lag phase duration $\left(t_{\text {LAG }}\right)$ using nonlinear models are determined by the shape of the curve and are independent of endogenous $\mathrm{CO}_{2}$ production. The results, however, are strongly associated with the estimated parameter " $m$ " or estimated gastric residual. ${ }^{11}$ In contrast, scintigraphy can be used to follow complete emptying of the stomach, an unequivocal end point. In our previous studies ${ }^{10}{ }^{12}$ using the conventional nonlinear model, we determined that accurate determination of the parameter " $m$ " in healthy subjects (that is a steady ${ }^{13} \mathrm{CO}_{2}$ excretion state) required at least six hours of breath collection. We anticipated that patients with impaired gastric emptying may require an even longer sampling time, suggesting the breath test may become impractical.

From a review of simultaneous scintigraphic and ${ }^{13} \mathrm{CO}_{2}$ cumulative excretion curves performed in nearly 70 healthy volunteers in our laboratory, we noted that the "tail" of the cumulative excretion curve often did not reach steady state conditions; moreover, this portion of the curve corresponded to a time when all of the ${ }^{99 \mathrm{~m}} \mathrm{Tc}$ isotope had emptied from the stomach. Thus optimizing the curve fit might represent a futile exercise unrelated to the process of emptying.

In the present study we aimed to develop a new mathematical model for breath data analysis that was independent of the parameter " $m$ " and would offer accuracy with shorter (three hours or less) sampling times. This new mathematical model was developed while assessing the accuracy of a breath test using a ${ }^{13} \mathrm{C}$ substrate consisting predominantly of the protein $\left[{ }^{13} \mathrm{C}\right]$ Spirulina platensis (described below). Subsequently, the model was further validated using the leave-one-out method. Finally, we performed the $\left[{ }^{13} \mathrm{C}\right] S$ platensis breath test in a simulated office based practice using a standardised prepacked $\left[{ }^{13} \mathrm{C}\right]$ biscuit commercial meal and compared the results with those of the $\left[{ }^{13} \mathrm{C}\right] S$ platensis egg meal.

Abbreviations used in this paper: $t_{1 / 2}$, half-emptying time; $\mathrm{t}_{\mathrm{LAG}}$, lag time. 


\section{Materials and methods}

SUBJECTS

Thirty healthy volunteers, aged 18-53 years (mean 34 (SE 1.6); 15 males, 15 females; median body mass index $23 \mathrm{~kg} / \mathrm{m}^{2}$ (range 18.7-39.1)), were recruited by public advertisement. None had previously undergone abdominal surgery other than appendicectomy. None was receiving medications. Females of childbearing potential had a negative pregnancy test within 48 hours of beginning the study. A clinical interview and physical examination were performed and none of the subjects was receiving medications that could influence gastrointestinal motility or autonomic function. Written informed consent was obtained before participation in the study which was approved by the Institutional Review Board and the Radiation Control Committee of the Mayo Clinic.

SUBSTRATE FOR ${ }^{13} \mathrm{CO}_{2}$ BREATH TEST

$\left(\left[{ }^{13} \mathrm{C}\right]\right.$ S PLATENSIS)

$S$ platensis is an edible blue-green alga used as a protein source in many parts of the world and sold as a food supplement in health food stores. ${ }^{13} 14$ It contains $50-60 \%$ protein, 30\% starch, and $10 \%$ lipid..$^{15}$ The $S$ platensis used in our study was grown as a pure monoculture in a closed hydroponics chamber in a medium containing inorganic salts and purged with pure ${ }^{13} \mathrm{CO}_{2}$. The resultant cells were uniformly labelled with ${ }^{13} \mathrm{C}$; the natural level of ${ }^{13} \mathrm{C}$ in the environment (about 1\%) was increased to $99 \%$ in the substrate used. When metabolised, the proteins, carbohydrates, and lipids of the $S$ platensis give rise to respiratory $\mathrm{CO}_{2}$ that is enriched in ${ }^{13} \mathrm{C}$. Because the contents of the algal cells are not freely diffusible, incorporation of labelled $S$ platensis into a solid phase meal occurs easily and represents the digestive state of the solid food matrix within which it is contained.

\section{SCINTIGRAPHY AND $\left[{ }^{13} \mathrm{C}\right] S$ PLATENSIS BREATH TEST METHODS \\ Radioscintigraphic marker and test meal}

The test meal comprised eggs dosed with 200 $\mathrm{mg}$ of $\left[{ }^{13} \mathrm{C}\right] S$ platensis (Meretek Diagnostics, Inc., Houston, Texas, USA) and $0.5 \mathrm{mCi}{ }^{99 \mathrm{~m}} \mathrm{Tc}$ sulphur colloid. The egg whites were mixed with $0.5 \mathrm{mCi}{ }^{99 \mathrm{~m}} \mathrm{Tc}$ sulphur colloid. The egg meal was placed on a slice of whole wheat bread and given with a glass of skimmed milk for a total caloric value of $220 \mathrm{kcal}$ with a nutrient composition of $35 \%$ protein, $40 \%$ carbohydrate, $25 \%$ fat, and $2.6 \mathrm{~g}$ of fibre.

\section{Scintigraphic and breath test methods}

After an overnight fast, scintigraphic scanning with anterior and posterior cameras was performed with the patient standing. Imaging began at the start of the test meal and scans were obtained every 15 minutes for two hours and then every 30 minutes for six hours. Breath samples were taken at baseline before the meal and followed the same time schedule as the scintigraphic technique. Breath samples were collected and stored in duplicate in glass vacutainers using a straw to blow into the bottom of the tube. After restoppering the tubes, the ${ }^{13} \mathrm{C}$ breath content was determined in a centralised laboratory (Dr P D Klein, Meretek Diagnostics) by isotope ratio mass spectrometry. ${ }^{16}{ }^{17}$

Standard meal study using $\left[{ }^{13} \mathrm{C}\right]$ S platensis biscuit About seven months (5-9 months) after the $\left[{ }^{13} \mathrm{C}\right] S$ platensis in egg meal studies, another study using a standardised meal including a $\left[{ }^{13} \mathrm{C}\right] S$ platensis biscuit (Meretek Diagnostics, Inc.) was performed in 27 of the 30 healthy subjects. After an overnight fast they ingested the standardised meal consisting of a $60 \mathrm{~g}$ rye roll (160 calories), 30 g cream cheese (90 calories), and $120 \mathrm{ml}$ white grape juice (80 calories). The rye roll contained $200 \mathrm{mg}$ of $\left[{ }^{13} \mathrm{C}\right] S$ platensis. Breath samples were collected at baseline (before meal) and at 75, 90, and 180 minutes, and gastric $t_{1 / 2}$ and $t_{\mathrm{LAG}}$ were estimated using the same mathematical method.

\section{DATA ANALYSIS}

Scintigraphic data

A region of interest was drawn around the stomach on the anterior and posterior images for each time frame. To correct for tissue attenuation, the counts in each region were multiplied together and the square root of the product was taken to obtain the geometric mean. Gastric emptying was summarised using a power exponential $\operatorname{model}^{1}$ : $\operatorname{prop}_{t}$ $=\exp \left[-\left(k^{\star} t\right)^{b}\right]$

where prop $_{t}$ is the proportion remaining in the stomach at time $t$. The index $k$ is an expression of the instantaneous slope of the curve and $b$ is an index for the shape of the curve $(b=1$ implies a simple exponential emptying model). The parameters $k$ and $b$ were estimated using the nonlinear least squares (NLIN) procedure in the SAS software package. ${ }^{18}$ The duration of the lag phase was defined as the time when $10 \%$ of the test meal was emptied from the stomach. The gastric half-emptying time $\left(t_{1 / 2 \mathrm{~S}}\right)$ and lag phase duration ( $t_{\text {LAGS }}$ ) were derived after estimating $k$ and $b$ for each subject, solving the above formula for time $t$, and using 0.5 and 0.1 , respectively, for prop $_{t}$.

\section{$\left[{ }^{13} \mathrm{C}\right] S$ platensis breath test data}

${ }^{13} \mathrm{C}$ enrichment determined by isotope ratio mass spectrometry was expressed as the delta per mil difference between the ${ }^{13} \mathrm{CO}_{2} /{ }^{12} \mathrm{CO}_{2}$ ratio of the sample and standard. ${ }^{13} \mathrm{CO}_{2}$ in the breath samples was calculated as atom percent excess (percentage ${ }^{13} \mathrm{CO}_{2}$ in total $\mathrm{CO}_{2}$ above background ${ }^{13} \mathrm{CO}_{2}$ concentration in nature) as in previous studies. ${ }^{18-20}$ The results of the breath test were presented as a percentage of ${ }^{13} \mathrm{CO}_{2}$ recovery per hour and as a cumulative value over six hours. ${ }^{13} \mathrm{CO}_{2}$ production was assumed to be $300 \mathrm{mmol}$ per square metre of body surface area per hour as published by Ghoos et al. ${ }^{6}$ Body surface area was calculated using a validated weight-height formula.

To calculate the quantity of ${ }^{13} \mathrm{C}$ appearing in breath per unit time, delta over baseline (DOB) was used: ${ }^{13} \mathrm{C} \quad(\mu \mathrm{M} / \mathrm{min})=\mathrm{DOB} \times$ $0.0112372 \times \mathrm{CO}_{2}$ production, where 0.0112372 is the isotopic abundance of the limestone standard, Pee Dee Belemnite, and $\mathrm{CO}_{2}$ 

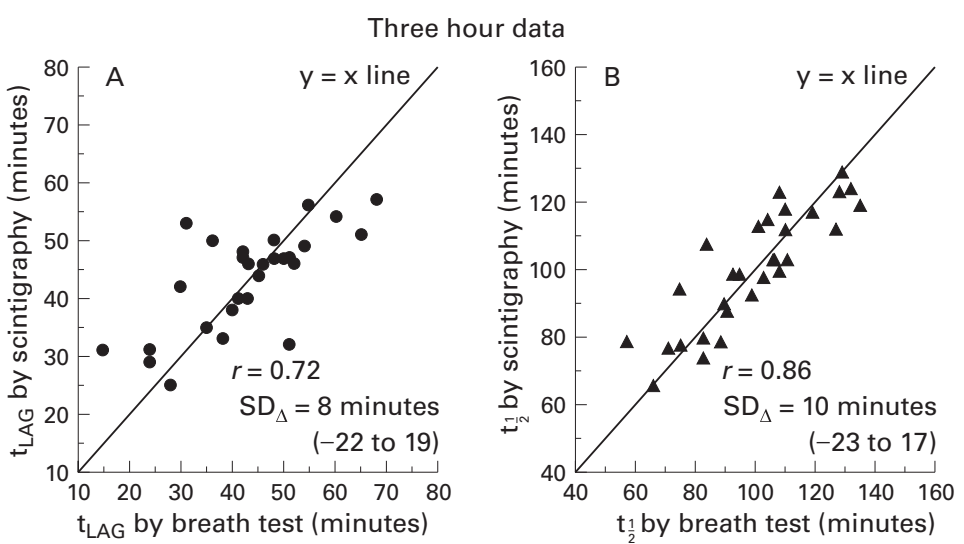

Three sample data
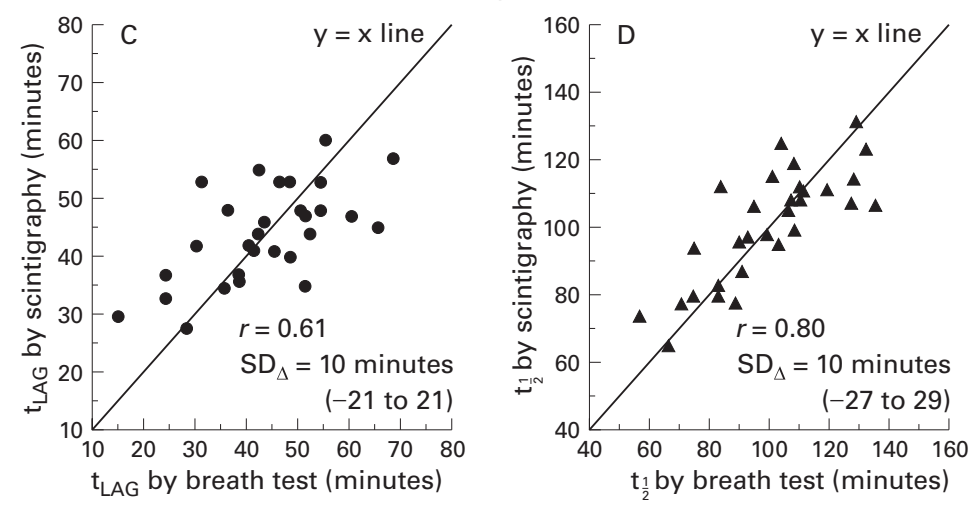

Figure 1 Association between lag phases ( $t_{L A G}$ ) and half-emptying times $\left(t_{1 / 2}\right)$ for scintigraphy values compared with estimates from a generalised linear regression model based on breath test values from the first three hours of data $(A, B)$ and for two time points from the first three hours of sampling $(C, D$; the $y=x$ line is shown for comparison). Note the significant correlation between estimates. The variation in differences between estimates by the two methods is expressed as $S D_{4}$ and range.

production was corrected for individual basal metabolic rates according to age $(<3,3-10$, $10-18,18-30,30-60,>60$ years) and gender as determined by Schofield ${ }^{21}$
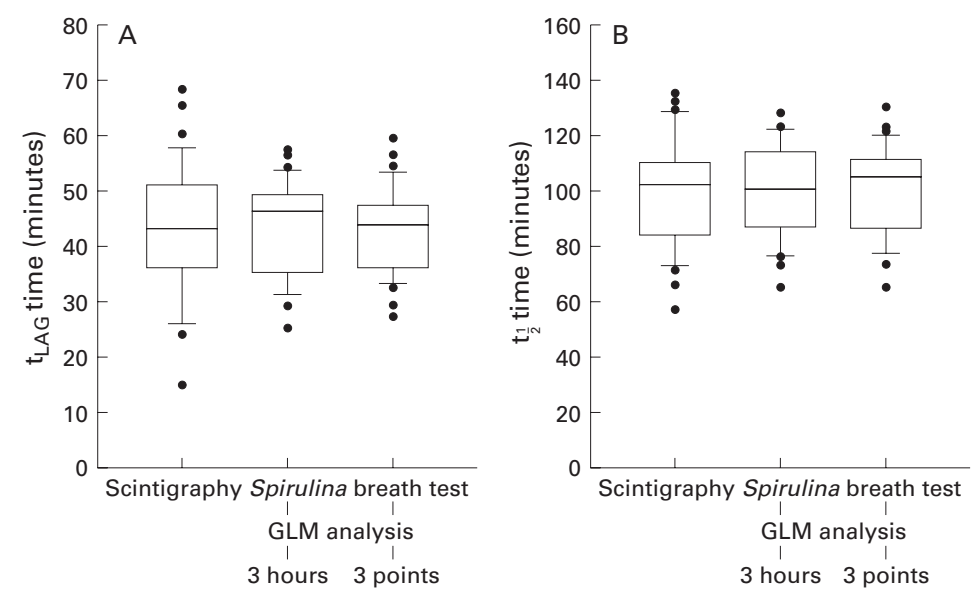

Figure 2 Comparison of gastric lag phase duration $\left(t_{L A G}\right)(A)$ and half-emptying times $\left(t_{1 / 2}\right)(B)$ from scintigraphy and $\left[{ }^{13} \mathrm{C}\right] S$ platensis breath tests using the generalised linear regression models (GLM), shown as median values (bars), interquartile ranges (boxes), range from 10th to 90th percentiles (bar caps), and practical data over the 10th to 90th percentiles (dots) for scintigraphy and breath tests. Note the excellent agreement between scintigraphy and generalised linear models.
STATISTICAL ANALYSIS

Generalised linear regression model to predict scintigraphic estimates of gastric half-emptying time and lag phase using breath test values A generalised linear multiple regression analysis ${ }^{19}$ was used to develop a model for predicting the scintigraphic gastric emptying estimates for $t_{1 / 2}$ and $t_{L A G}$ using ${ }^{13} \mathrm{C}$ values from breath samples obtained over the first three hours after the meal. In this generalised linear model approach, $t_{1 / 2}$ and $t_{L A G}$ values were assumed to follow a gamma distribution (positively skewed distribution) to account for a common situation in clinical practice where data from patients with gastroparesis, or dumping syndrome, often lead to a skewed distribution of gastric emptying $\mathrm{t}_{1 / 2}$ and $\mathrm{t}_{\mathrm{LAG}}$ values. The link function used to relate the linear predictor (weighted combination of ${ }^{13} \mathrm{C}$ values at the multiple time points) to scintigraphically observed $t_{1 / 2}$ (or $t_{L A G}$ ) values was the inverse (reciprocal) function. A preliminary analysis of the (reciprocally) transformed $t_{1 / 2}$ and $t_{L A G}$ values using a simple stepwise multiple regression model (maximum $r^{2}$ method) provided candidate subsets of breath sample times to consider as "reduced models" (that is, fewer time points) in the generalised regression (gamma) model analysis.

As it is possible that evaluation of models to estimate $t_{L A G}$ and $t_{1 / 2}$ may give an overly optimistic assessment when based on the same data, ${ }^{20}$ an internal cross validation analysis was used to assess the results of the "reduced models". Thus a "leave-one-out" approach" was used to obtain the breath sample prediction for each subject. In this analysis, each individual subject is left out of the calculations to estimate the regression parameters of the linear predictor for the gamma regression model; then the predicted value for the subject omitted from the model (or left out) is computed using the regression model results based on the remaining subjects included (or left in) the model. This is done repeatedly with each subject in turn being left out and used as a (quasi) external validation observation.

Comparisons of the adequacy of fit of the models between the full six hour data compared with the three hour data or the "reduced models" were based on the difference in log likelihood values for each model. Similarly, the adequacy of fit for the three hour data and the "reduced models" were compared.

In addition, estimates of $t_{1 / 2}$ and $t_{L A G}$ by the full and "reduced models" were compared using a (non-parametric) Wilcoxon signed rank test of the differences resulting from different estimation methods (for example a paired comparison of the absolute values of (scintigraphic $t_{1 / 2}$ minus breath sample estimated $\left.t_{1 / 2}\right)$ ). The correlation between scintigraphically determined values (observed values) and predicted values (for the various estimation methods) were computed, and the distribution of simple residuals (observedpredicted) summarised.

The distributions of $t_{1 / 2}$ and $t_{L A G}$ estimates from the breath test using either the egg meal 

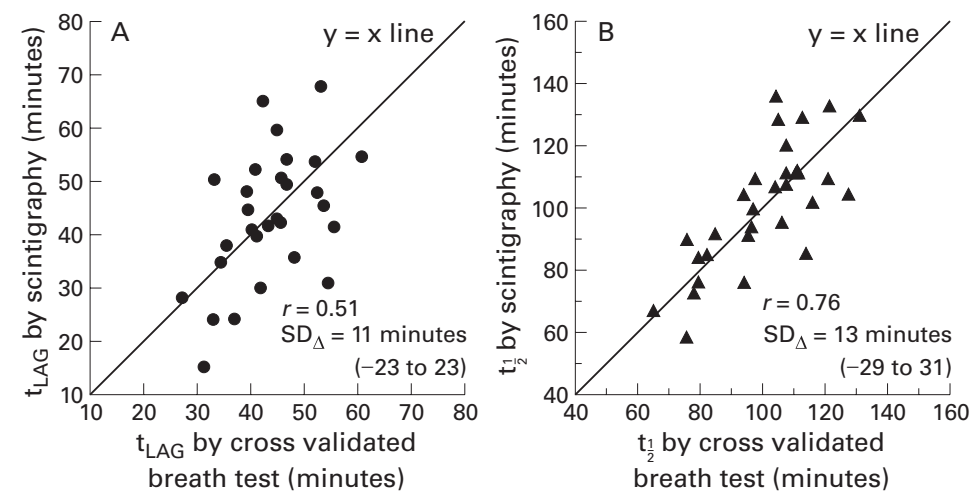

Figure 3 Cross validation results for generalised linear regression reduced model using the leave-one-out approach. Note the significant correlation between estimates. The variation in differences between estimates by the two methods is expressed as $S D$ and range. Cross validated estimate of the differences between scintigraphic $t_{112}$ and estimated $t_{1 / 2}$ from the reduced model using three time points from the breath test had a standard deviation of 13 minutes ( -29 to 31 ) while that for $t_{L A G}$ was 11 minutes ( -23 to 23).

or the biscuit meal in 27 healthy subjects were compared.

\section{Results}

COMPARISON OF GASTRIC EMPTYING INDICES BETWEEN SCINTIGRAPHY AND THE BREATH TEST USING A GENERALISED LINEAR REGRESSION MODEL PREDICTING SCINTIGRAPHIC RESULTS Gastric emptying by scintigraphy yielded mean values of 43 (SD 12) minutes for $t_{\text {LAGS }}$ and 100 (20) minutes for $t_{1 / 2 s}$. The generalised linear regression models predicting scintigraphic $t_{\mathrm{LAG}}$ based on the entire six hour and the first three hour breath test data for ${ }^{13} \mathrm{C}$ breath excretion did not differ significantly $(r=0.79$ and 0.72 , respectively). Twice the difference in log likelihood values (which is approximated by a chi-square distribution) was 5.0 on 6 degrees of freedom $(\mathrm{p}=\mathrm{NS})$. The standard deviation of the difference between the observed $t_{\mathrm{LAG}}$ and the predicted values computed using the three hour breath test data was eight minutes (range -22 to 19) (fig 1A). The generalised linear models predicting scintigraphic $t_{1 / 2}$ based on the entire six hour and the first three hour breath test data for ${ }^{13} \mathrm{C}$ breath excretion did not differ significantly $(r=0.91$ and 0.86 , respectively; difference in log likelihood, 7.5 on 6 degrees of freedom; NS). The standard deviation of the differences between $t_{1 / 2}$ from scintig-
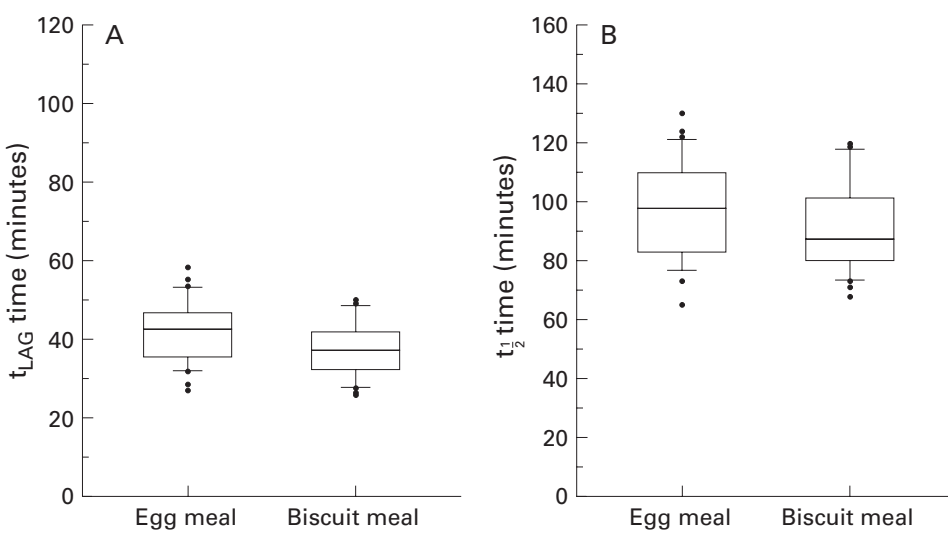

Figure 4 Distribution of $t_{L A G}(A)$ and $t_{1 / 2}(B)$ using $\left[{ }^{13} C\right] S$ platensis in an egg meal and in a biscuit meal in 27 healthy subjects, shown as median values (bars), interquartile ranges (boxes), range from 10th to 90th percentiles (bar caps), and observed data over 10th to 90 th percentiles (dots). Note the good agreement between results from the two meals. raphy and the predicted value computed using the three hour breath test data was 10 minutes (range -23 to 17 ) (fig $1 \mathrm{~B}$ ).

The generalised linear regression models identified three time points as being significant predictors of $\mathrm{t}_{\mathrm{LAG}}\left(75,180\right.$ minutes) and $\mathrm{t}_{1 / 2}(90$, 180 minutes). The model predicting scintigraphic $t_{L A G}$ using two data points (reduced model: 75,180 minutes) was less accurate $(r=0.61 v$ full model $r=0.72$ ) (fig 1A, C), although the difference in log likelihood was 4.6 on 8 degrees of freedom (NS). The standard deviation of differences in $t_{\mathrm{LAG}}$ between the scintigraphy value and the predicted value computed using the "reduced model" was also 10 minutes (range -21 to 21 ). The generalised regression model predicting scintigraphic $t_{1 / 2}$ based on just two data points ("reduced model": 90, 180 minutes) for ${ }^{13} \mathrm{CO}_{2}$ breath excretion did not differ significantly from the full model ( $r=0.86 v$ full model $r=0.80$; log likelihood 5.8 on 8 degrees of freedom; NS) (fig 1B, D). The standard deviation of the differences in $t_{1 / 2}$ from scintigraphy and the predicted value computed using the "reduced model" was 10 minutes (range -27 to 29 ).

A summary of the mathematical models using data from three breath test samples (75, 90, 180 minutes) is: $t_{\mathrm{LAG}}=1 / \mathrm{LP}_{\mathrm{LAG}}$, where $\mathrm{LP}_{\mathrm{LAG}}=0.0250+0.0063^{13} \mathrm{C}_{75}-0.0032^{13} \mathrm{C}_{180}$; and for $t_{1 / 2}: \mathrm{t}_{1 / 2}=1 / \mathrm{LP}_{1 / 2}$, where $\mathrm{LP}_{1 / 2}=0.0097+$ $0.0021{ }^{13} \mathrm{C}_{90}-0.0012^{13} \mathrm{C}_{180}$.

In these formulas, $t_{L A G}$ and $t_{1 / 2}$ are predicted $t_{L A G}$ and $t_{1 / 2}$ using breath test concentrations in $\mu \mathrm{mol} / \mathrm{min}$ at the specific times 75,90 , and 180 minutes; $\mathrm{LP}_{\mathrm{LAG}}$ and $\mathrm{LP}_{1 / 2}$ are the linear predictors (that is, weighted sums of breath test concentrations); and ${ }^{13} \mathrm{C}_{\mathrm{i}}$ is the excreted quantity of ${ }^{13} \mathrm{C}(\mu \mathrm{mol} / \mathrm{min})$ for time $t_{\mathrm{i}}=75,90$, or $180 \mathrm{~min}-$ utes.

GASTRIC EMPTYING PARAMETERS IN HEALTHY SUBJECTS USING BREATH TEST AND SCINTIGRAPHY

Figure 2 summarises gastric emptying indices for 30 healthy volunteers from scintigraphy and various breath test results (a generalised linear regression model using the three hour data and a generalised linear regression "reduced model" using only two time points). The predicted $t_{\mathrm{LAG}}$ and $t_{1 / 2}$ values from the generalised linear regression ("reduced models") were similar to the scintigraphic values (fig 2).

CROSS VALIDATION ANALYSIS OF THE GENERALISED LINEAR REGRESSION REDUCED MODEL

Figure 3 summarises the cross validation assessment of the "reduced model" for estimating the scintigraphic gastric emptying parameters $\left(t_{\text {LAG }}\right.$ and $\left.t_{1 / 2}\right)$. The standard deviation of the differences for $t_{\text {LAG }}$ was 11 minutes (range -23 to 23 ) and for $t_{1 / 2}, 13$ minutes (range -29 to 31 ). Figure 4 indicates a slightly broader distribution of residuals compared with those in fig $3 \mathrm{C}$ and $\mathrm{D}$. However, the cross validated predicted values showed little change in the correlation coefficients. 
Table 1 Normal values of gastric emptying indices of the $\left[{ }^{13} \mathrm{C}\right] \mathrm{S}$ platensis breath test in healthy volunteers (minutes)

\begin{tabular}{llclll}
\hline Test meal (No) & Variable & Median & Q1-Q3 & 10-90th & Min-Max \\
\hline Egg meal (30) & $\mathrm{t}_{\text {LAG }}$ & 43 & $36-47$ & $33-53$ & $27-59$ \\
Biscuit meal (27) & $\mathrm{t}_{1 / 2}$ & 104 & $86-111$ & $77-120$ & $65-130$ \\
& $\mathrm{t}_{\text {LAG }}$ & 38 & $33-42$ & $28-49$ & $26-51$ \\
& $\mathrm{t}_{1 / 2}$ & 88 & $80-102$ & $73-118$ & $67-120$ \\
\hline
\end{tabular}

Q1-Q3, interquartile range; 10-90th, 10th to 90th percentile values; $t_{\text {LAG }}$, lag time; $t_{1 / 2}$, half-emptying time. estingly, these time points are earlier than the time when one would anticipate errors from the redistribution of ${ }^{13} \mathrm{C}$ from the body's bicarbonate pool which occurs typically more than three hours after a meal.

Using the generalised linear regression "reduced model", breath samples were needed at only four times: baseline, 75, 90, and 180 minutes after the meal, with three data points each for $t_{\text {LAG }}$ (baseline, 75, and 180 minutes) and $t_{1 / 2}$ (baseline, 90, and 180 minutes). Moreover, the calculations were simplified relative to the nonlinear approach; predicted $t_{\mathrm{LAG}}$ and $\mathrm{t}_{1 / 2}$ can be estimated using a pocket calculator. This simplified method can be applied in epidemiological or multicentre studies because of its safety, simplicity, accuracy, and low cost relative to scintigraphy.

As our model was developed based on data from 30 healthy volunteers, it is possible that our approach reflects only physiological gastric emptying. However, because the model incorporated a non-Gaussian data distribution, we anticipate it would be similarly accurate in disease states, particularly in delayed gastric emptying. We have validated the use of the model in diabetic patients using a $\left[{ }^{13} \mathrm{C}\right]$ octanoic acid meal as the source of ${ }^{13} \mathrm{C} \cdot{ }^{23}$ The relative accuracy of the test using ${ }^{13} \mathrm{C}$ spirulina substrates in disease states requires further study.

A final departure from previous studies in this analysis was the use of the actual quantity of ${ }^{13} \mathrm{C}$ appearing in breath per minute. This was used to further simplify the calculation, obviating the need to collect all data points for the cumulative excretion plot. A delta over baseline value or a percentage of ${ }^{13} \mathrm{CO}_{2}$ recovery per hour can also be used, but we found that actual ${ }^{13} \mathrm{C}$ values reflected the most accurate overall results.

In summary, new calculations render the stable isotope $\left[{ }^{13} \mathrm{C}\right] S$ platensis breath test comparable with scintigraphy for estimating gastric emptying in healthy volunteers. The normal values for a standardised preprepared meal containing ${ }^{13} \mathrm{C}$ were estimated. These approaches need to be applied in disease states and may ultimately enable the development of an office or field based non-radioactive test to measure gastric emptying of solids in humans. a breath test is used. Following our observation that the early portion of the cumulative ${ }^{13} \mathrm{CO}_{2}$ breath curves was generally linear (and reciprocal to the scintigraphic emptying curve), we sought the time points during the three hour period of breath sampling which best reflected the scintigraphic estimates of gastric emptying in healthy subjects. Using this method we determined that three breath samples during the first three hours provided essentially equivalent information compared with estimates from all breath samples obtained during the three hour test. We have shown, using a generalised linear model approach, that the three hour data were essentially equivalent to the estimates from the six hour breath test, and that both gave good estimates of $t_{\mathrm{LAG}}$ and $\mathrm{t}_{1 / 2}$ determined by scintigraphy. These time points (particularly at 90 and 180 minutes) most closely reflected the gastric half-emptying time. Inter-
This study was supported in part by a grant from Meretek Laboratories, Houston, Texas, by a grant to Meretek from the Janssen Research Foundation and by General Clinical Research Center grant (No RR00585) and RO1-DK54681-01 and K24DK02638-01 (Dr M Camilleri) from the National Institutes of Health. The authors thank Mrs Cindy Stanislav for excellent secretarial assistance.

Potential conflict of interest: Dr P D Klein is an employee of Meretek Diagnostics, Inc. Two US patents have been awarded to Meretek Diagnostics, Inc. (Nos 5,707,602 and 5,785,949) covering the use of ${ }^{13} \mathrm{C}$ spirulina ( $S$ platensis) in solid and liquid phase gastric emptying measurements.

1 Camilleri M, Malagelada J-R, Brown ML, Becker G, Zinsmeister AR. Relation between antral motility and gastric emptying of solids and liquids in humans. Am $\mathcal{F}$ Physiol 1985;249:G580-5.

2 Camilleri M, Zinsmeister AR, Greydanus MP, Brown ML, Proano M. Towards a less costly but accurate test of gastric emp.

3 Thomforde GM, Camilleri M, Phillips SF, Forstrom LA. Evaluation of an inexpensive screening scintigraphic test of gastric emptying. F Nucl Med 1995;36:93-6. 
4 Meyer JH, Ohashi H, Jehn D, Thomson JB. Size of liver particles emptied from the human stomach. Gastroenterology 1981:80:1489-96.

5 Elashoff JD, Reedy TJ, Meyer JH. Analysis of gastric emptying data. Gastroenterology 1982;83:1306-12.

6 Ghoos YF, Maes BD, Geypens BJ, et al. Measurement of gastric emptying rate of solids by means of a carbon-labeled octanoic acid breath test. Gastroenterology 1994;104:1640

7 Maes BD, Ghoos YF, Geypens BJ, Hiele MI, Rutgeerts PJ. Relation between gastric emptying rate and energy in in children compared with adults. Gut 1995;36:183-8.

8 Maes BD, Ghoos YF, Geypens BJ, Hiele MI, Rutgeerts PJ. Influence of octreotide on the gastric emptying of solids and liquids in normal healthy subjects. Aliment Pharmacol Ther 1995;9:11-18.

9 Murphy MS, Eastham EJ, Nelson R, Aynsley-Green A. Noninvasive assessment of intraluminal lipolysis using a ${ }^{13} \mathrm{CO}_{2}$ breath test. Arch Dis Child 1990;65:574-8.

10 Choi M-G, Camilleri M, Burton DD, Zinsmeister AR, Forstrom LA, Nair KS. Reproducibility and simplification of ${ }^{13} \mathrm{C}$-octanoic acid breath test for gastric emptying of solids. Am $\mathcal{F}$ Gastroenterol 1998:93:92-8.

11 Choi MG, Camilleri M, Zinsmeister AR. Reply to letter to the editor. Gastroenterology 1998;114:858-9.

12 Choi MG, Camilleri M, Burton DD, Zinsmeister AR, Forstrom LA, Nair KS. $\left[{ }^{13} \mathrm{C}\right]$ octanoic acid breath test for gastric emptying of solids: accuracy, reproducibility, and comparison with scintigraphy. Gastroenterology 1997;112:115562.
13 Ciferri O. S. platensis, the edible microorganism. Microbiol Rev 1983;47:551-78

14 Dillon JC, Phuc AP, Dubacq JP. Nutritional value of the alga S. platensis. World Rev Nutr Diet 1995;77:32-46.

15 Ciferri O, Tiboni O. The biochemistry and industrial potential of S. platensis. Ann Rev Microbiol 1985;39:503-26.

16 Klein PD. Clinical applications of ${ }^{13} \mathrm{CO}_{2}$ measurements. Fed Proc 1982;41:2698-701.

17 Schoeller DA, Schneider JF, Solomons NW, Watkins JB, Klein PD. Clinical diagnosis with the stable isotope ${ }^{13} \mathrm{C}$ in $\mathrm{CO}$ breath tests: methodology and fundamental consid$\mathrm{CO}_{2}$ breath tests: methodology and fundam

18 SAS Institute Inc. SAS/STAT Users Guide, version 6, 4th edn, vol 2. Cary, NC:SAS Institute, 1989:1135-94.

19 McCullagh P, Nelder JA. Models for data with constant coefficient of variation. In: McCullagh P, Nelder JA, eds. Generalized linear models. London: Chapman and Hall, 1983:149-67.

20 Lachenbruch PA, ed. Discriminant analysis. New York: Hafner Press, 1975:29-37.

21 Schofield WN. Predicting basal metabolic rate, new standards and review of previous work. Hum Nutr Clin Nutr 1985;39:5-41.

22 Degen LP, Phillips SF. Variability of gastrointestinal transit in healthy women and men. Gut 1996;39:299-305.

23 Lee JS, Camilleri M, Zinsmeister A, et al. Accurate, simple measurement of gastric emptying by ${ }^{13} \mathrm{C}$-octanoic acid breath test (OBT) in diabetics. Gastroenterology 1999;116: A966. 